\title{
Medication administration errors and contributing factors among nurses: a cross sectional study in tertiary hospitals, Addis Ababa, Ethiopia
}

\author{
Adam Wondmieneh ${ }^{1 *}$, Wudma Alemu ${ }^{2}$, Niguse Tadele ${ }^{2}$ and Asmamaw Demis ${ }^{1}$
}

\begin{abstract}
Background: Unsafe medication practices are the leading causes of avoidable patient harm in healthcare systems across the world. The largest proportion of which occurs during medication administration. Nurses play a significant role in the occurrence as well as preventions of medication administration errors. However, only a few relevant studies explored the problem in Ethiopia. Therefore, this study aimed to assess the magnitude and contributing factors of medication administration error among nurses in tertiary care hospitals, Addis Ababa, Ethiopia, 2018.

Methods: We conducted a hospital-based, cross-sectional study in Addis Ababa, Ethiopia. The study involved 298 randomly selected nurses. We used adopted, self-administered survey questionnaire and checklist to collect data via self-reporting and direct observation of nurses while administering medications. The tools were expert reviewed and tested on $5 \%$ of the study participants. We analyzed the data descriptively and analytically using SPSS version 24. We included those factors with significant $p$-values $(p \leq 0.25)$ in the multivariate logistic regression model. We considered those factors, in the final multivariate model, with $p<0.05$ at $95 \% \mathrm{Cl}$ as significant predictors of medication administration errors as defined by nurse self-report.

Result: Two hundred and ninety eight (98.3\%) nurses completed the survey questionnaire. Of these, 203 (68.1\%) reported committing medication administration errors in the previous 12 months. Factors such as the lack of adequate training $[\mathrm{AOR}=3.16 ; 95 \% \mathrm{Cl}(1.67,6)]$, unavailability of a guideline for medication administration $[\mathrm{AOR}=$ 2.07; $95 \% \mathrm{Cl}(1.06,4.06)]$, inadequate work experience $[\mathrm{AOR}=6.48 ; 95 \% \mathrm{Cl}(1.32,31.78)]$, interruption during medication administration $[A O R=2.42,95 \% \mathrm{Cl}(1.3,4.49)]$ and night duty shift $[A O R=5,95 \% \mathrm{Cl}(1.82,13.78)]$ were significant predictors of medication administration errors at $p$-value $<0.05$.

Conclusion and recommendation: Medication administration error prevention is complex but critical to ensure the safety of patients. Based on our study, providing a continuous training on safe administration of medications, making a medication administration guideline available for nurses to apply, creating an enabling environment for nurses to safely administer medications, and retaining more experienced nurses may be critical steps to improve the quality and safety of medication administration.
\end{abstract}

Keywords: Medication administration errors, Factors, Nurses

\footnotetext{
* Correspondence: wondmienehadam@gmail.com

'Department of Nursing, College of Health Sciences, Woldia University,

Woldia, Ethiopia

Full list of author information is available at the end of the article
}

(c) The Author(s). 2020 Open Access This article is distributed under the terms of the Creative Commons Attribution 4.0 International License (http://creativecommons.org/licenses/by/4.0/), which permits unrestricted use, distribution, and reproduction in any medium, provided you give appropriate credit to the original author(s) and the source, provide a link to the Creative Commons license, and indicate if changes were made. The Creative Commons Public Domain Dedication waiver (http://creativecommons.org/publicdomain/zero/1.0/) applies to the data made available in this article, unless otherwise stated. 


\section{Background}

Most people around the world will take medications at some point in their life to prevent or treat illness. However, medicines do sometimes cause severe harm, disability, and even death if taken incorrectly [1]. Medication errors are the leading causes of avoidable patient harm in the health care system across the world. In African health care setting medication errors are common health problems $[1,2]$. Medication administration errors (MAEs) are the most common types of medication errors posing dangerous consequences for patients, health professionals and health institutions $[2,3]$. The administration of medications are primarily the nurse's responsibility, on which spend up to $40 \%$ of their time on administering medications [4]. Nurses represent the last safety check in the chain of events in the medication administration process, and are the last safeguard of patient wellbeing [5].

Medication errors can occur at any of the phases of the medication use process: during prescribing, transcribing, dispensing and/ or administering. However, existing studies revealed that medication errors most frequently occur during the administration phase $[1,2,6]$. Most of the medications are administered by nurses [7]. The frequently perpetrated types of MAEs include wrong dose, wrong time, wrong drug, wrong route, omission of doses, wrong patient, lack of documentation, and technical errors [8-11].

To improve patient safety nurses should interrupt any medication errors before reaching the patient by adhering to the six rights of medication administration and reporting the medication administration error (MAEs) $[5,11,12]$. The six rights of medication administration are the right patient, right drug, right time, right route, right dose and right documentation [13]. Moreover, nursing and hospital managers should reduce the nursing staff workload, provide periodic training courses on the proper and safe administrations of medication and create a conducive environment for error reporting [10, $11]$.

The problem of MAEs is real incurring a serious threat to patient safety. Several studies and systematic reviews around the world showed the magnitude of MAE being still high $[2,6,11,14]$. Identifying and intervening the contributing factors of MAEs is one of the best strategies proposed to improve patient safety by reducing the magnitude of MAEs. The factors are commonly identified through medication error reporting. However, studies showed that nurses are reluctant to report MAEs $[8,10$, 15].

Medication errors are the most common type of medical errors that occur in hospitals, and in USA it is the eighth leading cause of death higher than car accidents, breast cancer, and AIDS combined [16, 17]. Medication errors, specially those that occur during administration are highly prevalent: each medication and each patient had at least one type of MAEs [9].

Medication errors are undoubtedly costly to patients, families, employers, hospitals, healthcare providers, and insurance companies. Patients are the primary survivor of MAEs. It profoundly affect patients in terms of morbidity, mortality, adverse drug event, additional cost and hospital stay [14]. Patients living in low-income countries experience twice as many disabilities due to medication related harm than those living in high-income countries [1]. A systematic review of adverse drug events and medication errors in African hospitals indicated that $8.4 \%$ of inpatients reported having experienced adverse drug events, while it contributed to $2.8 \%$ of admissions. Similarly, the mortality rate attributed to adverse drug events was $0.1 \%$ [2]. A direct observational study conducted in Egypt indicated $0.77 \%$ of inpatients being harmed by MAEs and needed either extended hospitalization or intervention [18]. Furthermore, in Ethiopia, 1.5\% of patients experienced actual adverse drug events associated with medication errors [19].

As a second survivor, the healthcare professionals suffer from medication errors. Nurses who involved in MAEs were found to suffer from emotional distress, lack of confidence, and punitive actions, especially when the error results in substantial patient harm. They also suffer from the loss of trusts of patients and patient families who experienced MAEs $[14,16]$. The health institutions as a third survivir suffer from medication errors through the increased cost of unplanned prolonged hospitalization and treatment to correct the errors. According to WHO 2017 report globally, the cost associated with medication errors has been estimated at 42 billion US Dollars annually [1, 16].

Generally, there are only a few relevant data on MAEs in developing and transitional countries, especially in Africa. In developing countries like Ethiopia with educational, economic, and trained labor problems, the issue is one of the least investigated and neglected health problems. Therefore the main aim of this study was to assess the occurrence of medication administration errors among nurses working in Addis Ababa Tertiary hospitals.

\section{Methods}

\section{Study design and setting}

We conducted a quantitative, institution-based, crosssectional study in tertiary care hospitals from February to March 2018 in Addis Ababa, Ethiopia. According to food, medicine and healthcare administration and control (FMHACA), (2017) report three hospitals namely Tikur Anbesa Specialized Hospital (TASH), St. Paul's Millennium Medical College (SPMMC) and Torhayiloch Comprehensive Specialized Hospital (TCSH) provide 
tertiary care. TASH has 986 Nurses with different qualification. SPMMC has 903 nurses with different qualifications. TCSH has been providing specialized service with 180 nurses.

\section{Population}

\section{Target population}

All nurses working in Addis Ababa tertiary care hospitals.

\section{Study sample}

Those randomly selected nurses.

\section{Eligibility criteria}

All nurses who have a minimum of diploma qualifications in nursing, a minimum of one-year work experience and involved in direct patient care were included in the study.

\section{Sample size determination and sampling technique}

We estimated the number of nurse participants using a single population proportion formula with the consideration of the following assumptions: a MAE rate of $71 \%$ [11], the margin of error 5, 95\% confidence level and non-response rate $10 \%$. The total sample size was calculated to be 303. The study participants of each hospital were selected by using simple random sampling technique. The observational data were collected by directly observing nurses continuously for $48 \mathrm{~h}$ during medication administration to patients in medical, surgical and emergency department.

\section{Study variables}

Socio-demographic characteristics of nurses and factors that contributed to MAEs were the independent variables whereas the occurance of MAE was the outcome variable.

\section{Sampling procedure}

We started the recruitment procedure with the acquisition of the lists of all nurses working in the three selected tertiary hospitals. Then, we proportionally allotted the sample size to the hospitals number of nurses: 145 nurses to Tikur Anbesa Specialized Hospital, 132 nurses to the St. Paul's Millennium Medical College, and 26 nurses to the Torhayiloch Comprehensive Specialized Hospital. Following the identification of the potential candidates using the inclusion criteria, we located each study units by using a simple random sampling method. Next, five trained data collectors (diploma nurses) administered the survey questionnaire to those candidates who would participate in the study. Finally, the data collectors, with the guidance of three supervisors, collected the tool back after checking its completeness and consistency.

To triangulate the data, we also conducted a continuous 48-h direct-observation of nurses while administering medications to inpatients in the medical, surgical and emergency units. Eight trained diploma nurses, with supervision by three trained BSc nurses, collected the observational data.

\section{Data collection instruments, and personnel}

The data were collected using a structured selfadministered questionnaire which was adopted from a questionnaire developed by a previous study [11]. The tool contained 43 items arranged in five sections. The first section focused on the demographic features of the participants, the second section on work-related experience, the third section on the rate and magnitude of MAEs, the forth section on the types of MAEs, and the last section on the predictors of MAEs defined by the nurse self-repot.

The direct-observation was conducted using a structured checklist adopted from the previous studies [9, 11]. It contained eight components. The observational checklist was used to gather data by observing nurses while medicating patients to assess whether they follow the six rights of medication administration or not. The questions were designed to elicit a 'yes' or 'no' response depending on the degree of nurses' adherence to the six rights of medication administration during the process of a medication administration.

\section{Data quality control}

We used the following measures to ensure the validity and reliability of the data: We obtained the data using two approaches (self-reporting and direct-observation: data triangulation). We adopted the survey questionnaire from the previous study [11] conducted in a very similar setting. It reported internal consistency reliability (Cronbach's alpha coefficient) of 0.84 , and a content validity index of 0.86 . We randomly selected the participants, which enhances the face validity of the study. Both tools underwent an expert review. We pre-tested both tools 2 weeks ahead of the actual study. The data collectors and supervisors were recruited from hospitals that were not included in the study, by emphasizing their experience on data collection and supervision. We trained both the data collectors and supervisors on the tools and data collection procedures. We used separate data collectors and supervisors in each survey. The direct-observation was blinded: the nurses, who were observed while administering medications were not informed that they were under observation to avoid Hawthorn's effect. Finally, the study group checked the completeness and consistencies of the tools on the spot and every night. 
Data entry, analysis, and presentation

The data were coded, cleaned, edited and entered into Epi data version 4.2 and exported to SPSS window version 24 for analysis. All variables with $P \leq 0.25$ in the bivariable analysis model were included in the final model of multivariable analysis in order to control all possible confounders. Model fitness was checked with the HosmerLemeshow test. Adjusted odds ratio with 95\% CI was estimated to identify the factors associated with MAEs using multivariable logistic regression analysis. Level of statistical significance was declared at $p$-value $<0.05$.

\section{Result}

\section{Demographic characteristics}

Two hundred and ninety-eight (98.3\%) nurses completed and returned the survey questionnaire. Of these, 198 (66.4\%) were female, 217 (72.8\%) were single, and 260 (87.2\%) had a BSc Degree in Nursing Science (Table 1).

\section{Work-related nurse characteristics}

The median work experience of the respondent was 2 years (ranged from one to 33). From the 298 nurses, 114 (38.3\%) worked in the day-shift, 166 (55.7\%) reported using guidelines to administer medications, 185 (62.1\%) were not trained on safe administration of medications, and 161 (54\%) faced interruption while administering medications (Table 2).

\section{Prevalence and types of medication administration error} Two hundred and three $(68.1 \%)$ nurses were involved in MAEs in the previous 12 months. Of these, 77 (37.9\%) claimed making MAE only once while 119 (58.6\%) made
MAEs 2-3 times and the remaining 7 (3.4\%) made MAEs more than four times.

Failure to administer medications at the right time was the most 117 (57.8\%) frequently breach in the rights of medication administration followed by breach in documentation $50(24.8 \%)$ and dose 46 (22.5\%) respectively. The administration of a medication through a route other than the ordered route was the fourth common incident: 38 (18.5\%) nurses admitted administering medications through wrong routes. Twenty four (11.7\%) nurses were administered the wrong medications; and $18(8.7 \%)$ nurses were administered medications to the wrong patients.

\section{Observational checklist result}

To triangulate the result of self-administered questionnaire, observational data were collected by observing nurses during medication administration continuously for $48 \mathrm{~h}$. The single medication administered by a nurse was considered as a single dose and totally 225 doses of medications were observed. Most (96\%) of the 225 directly observed doses involved a breach in the recipients' safety at least once (Table 3).

\section{Predictors of medication administration error}

Binary logistic regression was done to identify factors associated with medication administration errors. In multivariate logistic regression analysis factors that were significantly associated with MAEs were work experiences, availability of guideline for MA, take training, interruption during MA and Night shift.

Table 1 Demographic characteristics of nurses in tertiary hospitals, Addis Ababa, Ethiopia, 2018

\begin{tabular}{|c|c|c|c|c|}
\hline No. & Variables & Response & Frequency $(n=298)$ & Percentage (\%) \\
\hline \multirow[t]{5}{*}{1} & Age & $20-24$ years & 98 & 32.9 \\
\hline & & $25-29$ years & 146 & 49 \\
\hline & & $30-34$ years & 28 & 9.4 \\
\hline & & $\geq 35$ years & 26 & 8.7 \\
\hline & & Mean $=27.2$ years, $S D=5.1$ & & \\
\hline \multirow[t]{2}{*}{2} & Sex & Female & 198 & 66.4 \\
\hline & & Male & 100 & 33.6 \\
\hline \multirow[t]{3}{*}{3} & Marital status & Single & 217 & 72.8 \\
\hline & & Married & 79 & 26.5 \\
\hline & & Others $^{a}$ & 2 & 0.7 \\
\hline \multirow[t]{3}{*}{4} & Educational status & Diploma nurse & 25 & 8.4 \\
\hline & & BSc nurse & 260 & 87.2 \\
\hline & & MSc nurse & 13 & 4.4 \\
\hline \multirow[t]{2}{*}{5} & Educational award from & Government institution & 168 & 56.4 \\
\hline & & Private institution & 130 & 43.6 \\
\hline
\end{tabular}


Table 2 Work-related characteristics of nurses in tertiary hospitals, Addis Ababa, Ethiopia, 2018

\begin{tabular}{|c|c|c|c|c|}
\hline No. & Variables & Response & Frequency $(n=298)$ & Percentage (\%) \\
\hline \multirow[t]{3}{*}{1} & Work experience & $<10$ years & 269 & 90.3 \\
\hline & & $\geq 10$ years & 29 & 9.7 \\
\hline & & Median $=2$ years & & \\
\hline \multirow[t]{3}{*}{2} & Duration in the present unit & $\leq 3$ month & 28 & 9.4 \\
\hline & & 4-5 month & 26 & 8.7 \\
\hline & & $\geq 6$ month & 244 & 81.9 \\
\hline \multirow[t]{3}{*}{3} & Duty shift & Day shift & 114 & 38.3 \\
\hline & & Night shift & 79 & 26.5 \\
\hline & & Alternative shift & 105 & 35.2 \\
\hline \multirow[t]{3}{*}{4} & Nurse to patient ratio & $1-6$ & 72 & 24.2 \\
\hline & & $7-10$ & 106 & 35.6 \\
\hline & & $>10$ & 120 & 40.3 \\
\hline \multirow[t]{2}{*}{5} & Take training in MA practice & Yes & 113 & 37.9 \\
\hline & & No & 185 & 62.1 \\
\hline \multirow[t]{2}{*}{6} & Have guideline for MA & Yes & 166 & 55.7 \\
\hline & & No & 132 & 44.3 \\
\hline \multirow[t]{2}{*}{7} & Faced interruption during MA & Yes & 161 & 54 \\
\hline & & No & 137 & 46 \\
\hline \multirow[t]{2}{*}{8} & Communicate with another nurse before MA & Yes & 250 & 83.9 \\
\hline & & No & 48 & 16.1 \\
\hline
\end{tabular}

Table 3 The level of adherence to the six rights of medication administration, a direct observational survey in tertiary hospitals, Addis Ababa, Ethiopia, 2018 ( $n=225$ doses)

\begin{tabular}{|c|c|c|c|c|}
\hline$\overline{\text { No. }}$ & Variable & Response & Frequency $(n=225)$ & Percentage (100\%) \\
\hline \multirow[t]{2}{*}{1} & \multirow[t]{2}{*}{ Wash hands/ hand rub before the procedure } & Yes & 54 & 24.0 \\
\hline & & No & 171 & 76.0 \\
\hline \multirow[t]{2}{*}{2} & \multirow[t]{2}{*}{ Wear/ change glove } & Yes & 131 & 58.2 \\
\hline & & No & 94 & 41.8 \\
\hline \multirow[t]{2}{*}{3} & \multirow[t]{2}{*}{ Give medication to the right patient } & Yes & 191 & 84.9 \\
\hline & & No & 34 & 15.1 \\
\hline \multirow[t]{2}{*}{4} & \multirow[t]{2}{*}{ Administer the right medication } & Yes & 188 & 83.6 \\
\hline & & No & 37 & 16.4 \\
\hline \multirow[t]{2}{*}{5} & \multirow[t]{2}{*}{ Administer the right dose } & Yes & 173 & 76.9 \\
\hline & & No & 52 & 23.1 \\
\hline \multirow[t]{2}{*}{6} & \multirow[t]{2}{*}{ Administer through right route } & Yes & 193 & 85.8 \\
\hline & & No & 32 & 14.2 \\
\hline \multirow[t]{2}{*}{7} & \multirow[t]{2}{*}{ Administer medication at the right time } & Yes & 147 & 65.3 \\
\hline & & No & 78 & 34.7 \\
\hline \multirow[t]{2}{*}{8} & \multirow[t]{2}{*}{ Document necessary information } & Yes & 108 & 48 \\
\hline & & No & 117 & 52 \\
\hline \multirow[t]{2}{*}{9} & \multirow[t]{2}{*}{ Distractors } & Yes & 60 & 26.7 \\
\hline & & No & 165 & 73.3 \\
\hline
\end{tabular}


Nurses who didn't used guidelines for medication administration were two times more likely made MAEs than those who had used guidelines for medication administration $[\mathrm{AOR}=2.07,95 \%$ (CI: 1.06-4.06)]. Likewise, nurses who had not been trained on safe administration of medications were three times more likely made MAEs than those who had been trained $[\mathrm{AOR}=3.16$; $95 \%$ CI $(1.67$, 6.00)]. Nurses who were interrupted while administering medications were 2.42 times more likely committed MAEs than those who weren't interrupted administering medication $[\mathrm{AOR}=2.42,95 \% \mathrm{CI}(1.30,4.49)]$. Regarding work experience, nurses who had less than 10 years work experience were almost 6.5 times more likely committed MAEs than those nurses who have 10 years and above work experiences [AOR $=6.48$; 95\% CI $(1.32,31.78)]$. Finally, those nurses who were in night shift duty were five times more likely made MAEs than those nurses working in daytime shift $[\mathrm{AOR}=5,95 \% \mathrm{CI}(1.82,13.78)]$ (Table 4).

\section{Discussion}

One of the strategies to safeguard patient's safety and improve the quality of nursing care is the proper administration of medications. However, the finding of this study showed that the magnitude of MAE was high (68.1\%) in Addis Ababa tertiary hospitals. More than half of the medication errors occurred during administrations of medication and nurses are in the front line for the administrations of medication [20].

The prevalence of MAE in this self-reported study is relatively consistent with studies conducted in Iran teaching hospital (68.5\%), Indian tertiary hospital $(68.5 \%)$, three university hospitals of South Korea (69.6\%), and a study review conducted in Iran (70\%) [20-23]. On the other hand, the result of this finding was higher than those studies conducted in Turkey state hospital $(61.7 \%)$ and a systematic review conducted in England (54.4\%) [3, 24]. This difference might be due to a difference in the number of hospitals and number of researched clinical departments, in which some of the above studies were conducted in a single hospital and some studies were conducted in a single department. Furthermore, the above studies were conducted in developed countries, in which better computerized prescribing and recording system, high quality of health care services, voluntary error reporting and follow up are conducted.

The result of this study was higher than a study conducted in Felege Hiwot referral hospital, which was $56.4 \%$ [9]. The plausible justification for the difference might be the variation in the number of hospitals and researched clinical units. The above study was conducted in a single hospital inpatient department only. Additionally, the previous study used convenient sampling technique. However, the finding of this study is slightly lower than a study done in two public hospitals of southern Ethiopia (71\%) [11]. The possible explanation for this difference might be due to variation in the number and type of hospitals. The previous study was conducted in the two southern Ethiopia public hospitals. Additionally, there is a difference in sample size.

In this study, a total of 225 doses of medication administrations were observed. From these, 96\% involved at least one MAE. This finding is relatively consistent with studies conducted in Felege Hiwot referral hospital (98.1\%) and two public hospitals in southern Ethiopia $(99.7 \%)[9,11]$. On the other hand, the result of this study is three folds higher than a study conducted in the emergency department of Accra tertiary hospital (27.2\%) and more than two folds higher than a study conducted in the medical ward of Ain Shames university hospital in Egypt $(37.8 \%)$ [17, 25]. The difference might be due to variation in the study settings, in which the above studies conducted in a single hospital and in a single department. However, this study was conducted in all inpatient units of three hospitals.

This study revealed that magnitude of MAEs was considerably high in Addis Ababa tertiary hospitals. This indicates that the quality of nursing care in relation to medication administration did not appear to be up to the standard. The safety of the patient during medication administration was poorly maintained. Medication administration errors of this magnitude are likely to result in harming the patient and may erode public confidence in nursing care. Several studies and systematic reviews around the world in different countries reported likewise high magnitude of MAEs [2, 3, 6, 18].

The findings of both types of study showed that MAEs were a common health problem in the hospitals under study. The magnitude of MAE in self-reported study and observational study was 68.1 and $96 \%$ respectively. This result indicated that some participants made MAE but not report in the self-reported questionnaire. Similarly in this self-reported study $83.4 \%$ of nurses were not report medication errors to the concerned body. Furthermore different literatures also showed that majority of the medication errors were not reported [11, 24, 26].

Wrong time error (58.7\%) was the most frequent type of MAE detected in this study. This finding indicates that more than half of the medications were not administered at ordered time. When medications are not administered at the regularly scheduled time the patient may develop toxicities or resistance to the drugs. The finding of this study was similar to a study done in two southern Ethiopia hospitals (58.5\%) [11]. However, it was much lower than a study conducted in France (72.6\%) [27]. The difference likely to be due to the difference in the study setting (the previous study was conducted in a specified ward, while this study was conducted in all clinical departments of 
Table 4 Bivariate and multivariable logistic regression analysis of factors associated with MAE in tertiary hospitals, Addis Ababa, Ethiopia, 2018

\begin{tabular}{|c|c|c|c|c|c|}
\hline \multirow[t]{2}{*}{ Variables } & \multicolumn{2}{|c|}{ Medication administration error } & \multirow{2}{*}{$\begin{array}{l}\text { Bivariate logistic regression } \\
\text { COR }[95 \% \mathrm{Cl}]\end{array}$} & \multirow{2}{*}{$\begin{array}{l}\text { Multivariable logistic Regression } \\
\text { AOR }[95 \% \mathrm{Cl}]\end{array}$} & \multirow{2}{*}{$\begin{array}{l}P \text { - } \\
\text { Value }\end{array}$} \\
\hline & Yes & No & & & \\
\hline \multicolumn{6}{|l|}{$\overline{\text { Age }}$} \\
\hline 20-24 years & 77 (37.9\%) & $21(22.1 \%)$ & $5[2.0-12.49]$ & $0.57[0.10-3.30]$ & 0.53 \\
\hline $25-29$ years & 99 (48.8\%) & $47(49.5 \%)$ & 2.87 [1.22-6.73] & $0.35[0.06-1.95]$ & 0.23 \\
\hline 30-34 years & $16(7.9 \%)$ & $12(12.6 \%)$ & $1.8[0.62-5.35]$ & $0.41[0.08-2.09]$ & 0.28 \\
\hline$\geq 35$ years & $11(5.4 \%)$ & $15(15.8 \%)$ & 1.000 & 1.000 & \\
\hline \multicolumn{6}{|c|}{ Educational award from } \\
\hline Gov't institution & $106(52.2 \%)$ & $62(65.3 \%)$ & 1.000 & 1.000 & \\
\hline Private institution & $97(47.8 \%)$ & $33(34.7 \%)$ & $1.70[1.04-2.85]$ & $1.37[0.73-2.6]$ & 0.32 \\
\hline \multicolumn{6}{|l|}{ Work experience } \\
\hline$<10$ years & $193(95.1 \%)$ & $76(80 \%)$ & $4.80[2.15-10.85]$ & $6.48[1.32-31.78]$ & 0.021 \\
\hline$\geq 10$ years & $10(4.9 \%)$ & $19(20 \%)$ & 1.000 & 1.000 & \\
\hline \multicolumn{6}{|c|}{ Duration in the specific unit } \\
\hline$\leq 3$ month & $22(10.8 \%)$ & $6(6.3 \%)$ & $1.70[0.66-4.34]$ & $1.57[0.55-4.54]$ & 0.39 \\
\hline $4-5$ month & $14(6.9 \%)$ & $12(12.6 \%)$ & $0.54[0.24-1.22]$ & $0.54[0.20-1.48]$ & 0.23 \\
\hline$\geq 6$ month & $167(82.3 \%)$ & 77 (81.1\%) & 1.000 & 1.000 & \\
\hline \multicolumn{6}{|l|}{ Duty shift } \\
\hline Day shift & $56(27.6 \%)$ & $48(50.5 \%)$ & 1.000 & 1.000 & \\
\hline Night shift & $73(36 \%)$ & $6(6.3 \%)$ & $10.4[4.17-26.1]$ & 5 [1.82-13.78] & 0.002 \\
\hline Alternate shift & $74(36.4 \%)$ & 41 (43.2\%) & 1.54 [0.9-2.66] & $1.47[0.78-2.76]$ & 0.22 \\
\hline \multicolumn{6}{|l|}{ Took training } \\
\hline Yes & $56(27.6 \%)$ & $57(60 \%)$ & 1.000 & 1.000 & \\
\hline No & $147(72.4 \%)$ & $38(40 \%)$ & 3.9 [2.35-6.57] & 3.16 [1.67-60] & $<0.001$ \\
\hline \multicolumn{6}{|l|}{ Have guideline } \\
\hline Yes & $96(47.3 \%)$ & $70(73.7 \%)$ & 1.000 & 1.000 & \\
\hline No & $107(52.7 \%)$ & $25(26.3 \%)$ & $3.1[1.83-5.32]$ & 2.07 [1.06-4.06] & 0.03 \\
\hline \multicolumn{6}{|l|}{ Faced interruption } \\
\hline Yes & $124(61.1 \%)$ & 37 (39\%) & 2.46 [1.49-4.05] & 2.42 [1.30-4.49] & 0.005 \\
\hline No & 79 (38.9\%) & $58(61 \%)$ & 1.000 & 1.000 & \\
\hline \multicolumn{6}{|l|}{ Communicate } \\
\hline Yes & $165(81.3 \%)$ & 85 (89.5\%) & 1.000 & 1.000 & \\
\hline No & $38(18.7 \%)$ & $10(10.5 \%)$ & 1.96 [0.93-4.12] & $1.85[0.72-4.77]$ & 0.19 \\
\hline \multicolumn{6}{|l|}{ Report error } \\
\hline Yes & $38(18.7 \%)$ & $11(11.6 \%)$ & 1.000 & 1.000 & \\
\hline No & $165(81.3 \%)$ & $84(88.4 \%)$ & 0.57 [0.27-1.67] & $0.68[0.29-1.57]$ & 0.37 \\
\hline
\end{tabular}

Key:

COR Crude Odd Ratio

AOR Adjusted Odd Ratio

three hospitals). Additionally, there was a difference in data collection method. (The study in France used a direct observational method only. Whereas; this study used both a direct observational and self-reporting method).

On our study interruption during medication administration, lack of work experience and unavailability of a guideline for medication administration were significantly associated with MAEs. These findings were supported by studies conducted in Ethiopia Felege Hiwot Referral hospital and two public hospitals in southern Ethiopia $[9,11]$. A similar study conducted in Turkey indicated that interruption by telephone and questions being asked during medication administration were found to have contributed to MAEs [24]. Medication preparation and administration 
need concentration. Interruption occurs when a nurse is preparing and administering a medication, which could lead to an error. Interruption of these activities may lead to cognitive failure in relation to working memory and attentiveness. Moreover making the environment conducive for nurses prior to preparation and administrations of medication may reduce medication errors. The finding of this study showed that work experiences of nurses were significantly associated with MAEs. Studies conducted in Felege Hiwot Referral hospital and emergency department of southern Iran hospital indicated that there is a significant association between work experience and MAEs [9, 21]. Medication administration is one of the nursing practices and improved through experience. When nurses with experience can improve their skill and gain greater knowledge on safe medication administration practice. Moreover experienced nurses are familiar with different medications and procedures.

Lack of training and unavailability of guideline for safe medication administration practice were also significantly associated with medication administration errors. This finding is supported by WHO 2017 medication without harm strategies. In 2017 WHO develops strategies to improve patient safety through reductions of medication error up to $50 \%$ in the next 5 years from 2017 to 2022 [1]. From these strategies provide a guideline and strengthen health professionals capacity through skill building are the major ones. On the other hand, a study done in Egypt showed that MAEs was highly prevalent and all nurses had not taken training courses on safe medication administration practices and they haven't policies and procedures for medication administration [17]. Providing training is mandatory for medication error reduction because there is the discovery of the new disease, new medication, and new administration techniques. So to combine nursing practice with evidence training may serve as a bridge. Additionally, availability of guideline for medication administration may improve the quality of nursing care and reduce MAEs.

This study showed that medication administration time was significantly associated with MAEs. The odds of MAE among nurses administering medication during the day and night shift was 5:1[AOR $=5,95 \%$ CI $(1.82$, 13.78)]. This finding is supported by studies conducted in Felege Hiwot referral hospital of Ethiopia and Ain Shams University hospital of Egypt $[9,17]$. Nurses during night time may experience sleep deprivation, loss of concentration and exhaustion. Nurses use different strategies like Exercise for $30 \mathrm{~min}$, moderate caffeine consumption before night and taking nap to decrease sleep disturbance and increase attention during the night shift.

Reporting medication administration errors are just a tip of the iceberg to reduce medication administration errors. However, the findings of this study indicated that
$16.4 \%$ of participants reported MAEs. The result of this study is lower than studies conducted in Iran (55\%), two public hospitals in southern Ethiopia (24.7\%) and University of Gonder referral hospital (29.1\%) [10, 11, 26]. The difference might be due to fear of blame for the reported errors in the working unit, variation in the administration support and encouragement, a variation of nurses willingness to report errors and variations in the nurse to patient ratio. Additionally, there is a difference in the study setting.

\section{Limitations of the study}

$>$ The finding of this study is inferred to only tertiary hospitals found in Addis Ababa due to constraints of time and fund.

$>$ As it was a cross-sectional study, we couldn't draw a cause and effect relationship between the MAEs and the identified factors.

$>$ Finally the study was based on self-reported information and direct observation that may be prone to reporting bias and observer bias

\section{Conclusion}

In conclusion, based on our findings, the safety of inpatients receiving drug therapy in the studied hospitals was frequently breached. The provision and adherence to guidelines during medication administration, creating a conducive environment and training nurses on the safe administration of medication are critical to ensure the safety of patients during medication administration.

\section{Abbreviations \\ AIDS: Acquired Immuno-Deficiency Syndrome; AOR: Adjusted Odds Ratio; Cl: Confidence Interval; COR: Crude Odd Ratio; ICU: Intensive Care Unit; IV: Intravenous; MAE: Medication Administration Error; ME: Medication Error; SAQ: Self-Administered Questionnaire; SD: Standard Deviation; SPMMC: St. Paul's Millennium Medical College; SPSS: Statistical Program for Social Sciences; TASH: Tikur Anbesa Specialized Hospital; TCSH: Torhayiloch Comprehensive Specialized Hospital; US: United States; WHO: World Health Organization}

\section{Acknowledgements \\ The authors would like to thank managers, medical directors and staffs of the hospitals for giving the necessary information needed to conduct this study. Authors are also grateful for data collectors, supervisors and study subjects.}

\section{Authors' contributions}

AW was involved in the design of the study, data analysis, and interpretation of the findings, report writing and manuscript preparation of this project. WA and NT were involved in the design of the study, data analysis, and interpretation of the findings, report writing and manuscript preparation. AD was involved in the design of the study, data analysis, and interpretation of the findings, report writing and manuscript preparation of this project. All authors read and approved the final manuscript.

\section{Funding}

The research was funded by Addis Ababa University. The funder has no role in the development of the paper except finance. 


\section{Availability of data and materials}

All related data has been presented within the manuscript. The datasets used and/or analyzed during the current study are available from the corresponding author upon a reasonable request.

\section{Ethics approval and consent to participate}

We ensured the ethics of research by having the study approved by the IRB of the School of Nursing and Midwifery, College of Health Sciences, Addis Ababa University; getting permission from the respective hospitals; obtaining written informed consent from the respondents after briefing them about the purpose of the study.

\section{Consent for publication}

Not applicable.

\section{Competing interests}

The authors declare that they have no competing interests.

\section{Author details}

'Department of Nursing, College of Health Sciences, Woldia University, Woldia, Ethiopia. ${ }^{2}$ School of Nursing and Midwifery, College of Health Sciences, Addis Ababa University, Addis Ababa, Ethiopia.

Received: 18 January 2019 Accepted: 8 January 2020

Published online: 13 January 2020

\section{References}

1. World health organization Global patient saftey. Medication Without Harm: WHO; 2017. available at https://www.who.int/patientsafety/medicationsafety/medication-without-harm-brochure/en/.

2. Mekonnen AB, Alhawassi TM, McLachlan AJ, et al. Drugs - Real World Outcomes. 2018:5:1. https://doi.org/10.1007/s40801-017-0125-6.

3. Elliott R, Camacho E, Campbell F, Jankovic D, Martyn St James M, Kaltenthaler $\mathrm{E}$, et al. Prevalence and economic burden of medication errors in the NHS in England. Rapid evidence synthesis and economic analysis of the prevalence and burden of medication error in the UK 2018.

4. Dumo AMB. Factors affecting medication errors among staff nurses: basis in the formulation of medication information guide. IAMURE Int J Health Educ. 2012;1(1):88-149.

5. Ojerinde AC, Adejumo P. Factors associated with medication errors among health workers in university college hospital, Nigeria. J Nurs Health Sci. 2014; 3(3):22-3.

6. Alsulami Z, Conroy S, Choonara I. Medication errors in the Middle East countries: a systematic review of the literature. Eur I Clin Pharmacol. 2013; 69(4):995-1008.

7. Karna K, Sharma S, Inamdar S, Bhandari A. Study and evaluation of medication errors in a tertiary care teaching hospital-a baseline study. Int J Pharm Sci. 2012;4(5):587-93.

8. Kim KS, KWON SH, KIM JA, Cho S. Nurses' perceptions of medication errors and their contributing factors in South Korea. J Nurs Manag. 2011;19(3):346-53.

9. Feleke SA, Mulatu MA, Yesmaw YS. Medication administration error: magnitude and associated factors among nurses in Ethiopia. BMC Nurs. 2015;14(1):53.

10. Fathi A, Hajizadeh M, Moradi K, Zandian H, Dezhkameh M, Kazemzadeh S, et al. Medication errors among nurses in teaching hospitals in the west of Iran: what we need to know about prevalence, types, and barriers to reporting. Epidemiol Health. 2017;39:e2017022. https://doi.org/10.4178/epih. e2017022

11. Alemu W, Belachew T, Yimam I. Medication administration errors and contributing factors: a cross sectional study in two public hospitals in southern Ethiopia. Int J Africa Nurs Sci. 2017;7:68-74.

12. Flynn $L$, Liang $Y$, Dickson $G L$, Xie M, Suh DC. Nurses' practice environments, error interception practices, and inpatient medication errors. J Nurs Scholarsh. 2012;44(2):180-6.

13. Kozier B. Fundamentals of nursing: concepts, process and practice: pearson education; 2010.

14. Ayuk AG. A literature review of medication errors in the United States of America; 2016

15. Lee E. Reporting of medication administration errors by nurses in south Korean hospitals. Int J Qual Health Care. 2017;29(5):728-34.
16. Mahajan RP. Medication errors: can we prevent them? Br J Anaesth. 2011; 107(1):3-5.

17. Sheet F. Medical errors: Not just a headline: National partnership for women and families; 2009. p. 1.

18. al Tehewy M, Fahim H, Gad NI, El Gafary M, Rahman SA. Medication administration errors in a university hospital. J Patient Saf. 2016;12(1):34-9.

19. Dedefo MG, Mitike AH, Angamo MT. Incidence and determinants of medication errors and adverse drug events among hospitalized children in West Ethiopia. BMC Pediatr. 2016;16(1):81.

20. Kim PC, Shen JJ, Angosta AD, Frakes K, Li C. Errors associated with the rights of medication administration at Hospital Settings. J Hosp Health Care. 2018. Admin: JHHA-111. https://doi.org/10.29011/JHHA-111.000011.

21. Parihar M, Passi GR. Medical errors in pediatric practice. Indian Pediatr. 2008; 45(7):586.

22. Vazin A, Zamani Z, Hatam N. Frequency of medication errors in an emergency department of a large teaching hospital in southern Iran. Drug Healthc Patient Saf. 2014;6:179.

23. Mansouri A, Ahmadvand A, Hadjibabaie M, Kargar M, Javadi M, Gholami K. Types and severity of medication errors in Iran; a review of the current literature. DARU J Pharm Sci. 2013;21(1):49.

24. You M-A, Choe M-H, Park G-O, Kim S-H, Son Y-J. Perceptions regarding medication administration errors among hospital staff nurses of South Korea. Int J Qual Health Care. 2015;27(4):276-83.

25. Güneş ÜY, Gürlek Ö, Sönmez M. Factors contributing to medication errors in Turkey: nurses' perspectives. J Nurs Manag. 2014;22(3):295-303.

26. Franklin Acheampong ARTaBPA. Medication Administration Errors in an Adult Emergency Department of a Tertiary Health Care Facility in Ghana. J Patient Safety. 12(4):223-8. https://doi.org/10.1097/PTS.0000000000000105.

27. Bifftu BB, Dachew BA, Tiruneh BT, Beshah DT. Medication administration error reporting and associated factors among nurses working at the University of Gondar referral hospital, Northwest Ethiopia, 2015. BMC Nurs. 2016;15(1):43.

\section{Publisher's Note}

Springer Nature remains neutral with regard to jurisdictional claims in published maps and institutional affiliations.

Ready to submit your research? Choose BMC and benefit from:

- fast, convenient online submission

- thorough peer review by experienced researchers in your field

- rapid publication on acceptance

- support for research data, including large and complex data types

- gold Open Access which fosters wider collaboration and increased citations

- maximum visibility for your research: over $100 \mathrm{M}$ website views per year

At $\mathrm{BMC}$, research is always in progress.

Learn more biomedcentral.com/submissions 